\title{
Las revistas científicas médicas en México
}

\author{
Alfredo Ulloa-Aguirre, ${ }^{1 *}$ Ana Carolina Sepúlveda-Vildósola, ${ }^{2}$ Moisés Selman-Lama, ${ }^{1}$ \\ Luis Oñate-Oñate, ${ }^{1}$ Alejandro Treviño-Becerra, ${ }^{3}$ Carlos Oropeza-Abúndez, ${ }^{4}$ Sergio Sobrino-Cossío, ${ }^{5}$ \\ Pedro Gutiérrez-Castrellón ${ }^{5}$ y Héctor Esquivias-Zavala ${ }^{6}$ \\ ${ }^{1}$ Revista de Investigación Clínica-Clinical and Translational Investigation; ${ }^{2}$ Archives of Medical Research; ${ }^{3}$ Gaceta Médica de México; ${ }^{4}$ Salud Pública \\ de México; ${ }^{5}$ Cirugía y Cirujanos; ${ }^{6}$ Salud Mental. Ciudad de México, México
}

\section{Resumen}

En este simposio se describen las principales características de seis revistas científicas mexicanas reconocidas por el Journal Citation Reports: Archives of Medical Research, Revista de Investigación Clínica-Clinical and Translational Investigation, Gaceta Médica de México, Salud Pública de México, Cirugía y Cirujanos y Salud Mental. Se hace énfasis en sus aspectos históricos y organizacionales, así como en sus logros principales ante la comunidad científica nacional e internacional.

PALABRAS CLAVE: Revistas médicas. Archives of Medical Research. Revista de Investigación Clínica-Clinical and Translational Investigation. Gaceta Médica de México. Salud Pública de México. Cirugía y Cirujanos. Salud Mental.

\section{Scientific medical journals in Mexico}

\section{Abstract}

This symposium describes the main characteristics of six Mexican scientific journals indexed in the Journal Citation Reports: Archives of Medical Research, Revista de Investigación Clínica-Clinical and Translational Investigation, Gaceta Médica de México, Salud Pública de México, Cirugía y Cirujanos and Salud Mental. Particular emphasis is given to their historical and organizational aspects, as on well as their main achievements recognized by the national and international scientific community.

KEY WORDS: Medical journals. Archives of Medical Research. Revista de Investigación Clínica-Clinical and Translational Investigation. Gaceta Médica de México. Salud Pública de México. Cirugía y Cirujanos. Salud Mental.

\section{Introducción}

A pesar del relativamente lento desarrollo de la investigación científica en México como consecuencia de nuestra llegada tardía a la cultura europea y la falta de tradición científica, citando al doctor Ignacio Chávez (1947), las revistas científicas médicas de México tienen una larga historia y han desempeñado un papel muy importante en la difusión de los estudios de investigación biomédica y clínica realizados por investigadores mexicanos. Sin embargo, a partir de la década de los setenta del siglo pasado, la investigación en nuestro país se aceleró de forma importante al surgir la figura del investigador de tiempo completo y los programas de maestría y doctorado.

Es innegable que México ha hecho contribuciones de gran importancia al avance de la medicina, mismas que han sido publicadas en revistas tanto nacionales como internacionales. Las primeras incluyen a Gaceta Médica de México (1864 a la actualidad) y sus
Correspondencia:

*Alfredo Ulloa-Aguirre

E-mail: aulloaa@unam.mx 0016-3813/@ 2020 Academia Nacional de Medicina de México,
CC BY-NC-ND (http://creativecommons.org/licenses/by-nc-nd/4.0/).
Fecha de recepción: 03-07-2020

Fecha de aceptación: 27-07-2020

DOI: $10.24875 / G M M .20000466$
Gac Med Mex. 2020;156:619-635

Disponible en PubMed

www.gacetamedicademexico.com 
antecesores, el Periódico de la Academia de Mégico (1836-1840 y posteriormente de 1843 a 1851), el Periódico de la Sociedad Filoiátrica de México (18401841 y 1844-1845) y La Unión Médica de México (1856-1858), que documentan las contribuciones de la medicina mexicana a la literatura médica del siglo XIX, incluyendo textos de Miguel F. Jiménez en $L a$ Unión Médica de México (año 1, número 5, tomo 1), de Rafael Lucio Nájera en el Periódico de la Sociedad Filoiátrica de México (núm. 3, 1844) y de muchos otros pioneros de la investigación clínica del siglo XIX y la primera mitad del siglo $X X$, que pueden ser leídas en la interesante recopilación de Juan Somolinos publicada por la Universidad Nacional Autónoma de México en $1984{ }^{1}$

Entre las revistas de gran importancia en la primera mitad del siglo XX destaca la Revista Mexicana de Biología (1920-1935), en la que ilustres médicos publicaron estudios originales de gran importancia. Citamos, por ejemplo, los artículos de Eliseo Ramírez Ulloa sobre los cambios en la citología vaginal durante el ciclo menstrual de la mujer, de $1922^{2}$ y $1928,{ }^{3}$ trabajos que se adelantaron al célebre artículo de Georgios N. Papanikolaou publicado en 1933. ${ }^{4}$

Actualmente, el Sistema de Clasificación de Revistas Mexicanas de Ciencia y Tecnología incluye 49 revistas periódicas en el área de Medicina y Ciencias de la Salud. De estas, solo siete tienen un factor de impacto de acuerdo con el Journal Citation Reports, seis de las cuales (Archives of Medical Research, Revista de Investigación Clínica-Clinical and Translational Investigation-, Gaceta Médica de México, Salud Pública de México, Cirugía y Cirujanos y Salud Mental) se incluyen en esta sesión. La ausencia de la séptima revista, Annals of Hepatology, se debió a limitaciones en el tiempo programado para el simposio, por lo que de antemano ofrecemos una disculpa.

\section{Archives of Medical Research}

\section{Ana CARolina SEPÚlVEDA-VILDÓSOLA}

En 1970, el doctor Jorge Martínez Manatou y un grupo de investigadores del Instituto Mexicano del Seguro Social (IMSS) iniciaron la publicación de la revista Archivos de Investigación Médica, que rápidamente se convirtió en un medio para la difusión de los estudios científicos realizados en México. Después del doctor Martínez Manatou fueron editores de la revista José Luis Mateos Gómez (1971-1976), Fernando
Flores Barroeta y Juan García Ramos (1977), Juan Somolinos Palencia (1977-1991), Luis Benítez Bribiesca (1992-2015) y, a partir de 2016, Ana Carolina Sepúlveda Vildósola.

En 1992 se organizó una oficina con una plantilla de personal exclusivo para el manejo de la revista y se integró un comité editorial con investigadores del Instituto Mexicano del Seguro Social y de otras instituciones: Universidad Nacional Autónoma de México, Centro de Investigación y de Estudios Avanzados, Instituto Politécnico Nacional e Institutos Nacionales de Salud, para el arbitraje de los manuscritos recibidos. Años más tarde se inició con el envío de los manuscritos a revisión por árbitros internacionales, lo que permitió reducir los tiempos de revisión y dotó de mayor rigor y exigencia a las revisiones editoriales.

En 1972 se incluyó en el Current Contents con un factor de impacto inicial de 0.25. En 1994 fue aceptada en el Science Citation Index. Actualmente está indizada en Chemical Abstracts, Current Contents/Life Sciences, Medline, Lilacs (Literatura Latino-Americana e do Caribe em Ciências da Saúde), Embase, Science Citation Index, Excerpta Medica y Scopus. Su clasificación: Medicine, Research \& Experimental.

En sus inicios, la revista se publicó en español, agregándose posteriormente un resumen en inglés y a partir de 1992 se decidió publicar todo el contenido en inglés para favorecer su internacionalización. Al comienzo se publicaban cuatro números por año, que se distribuían por correo a algunas bibliotecas nacionales. En la actualidad publica siete números regulares y un número especial por año, con un promedio de 109 artículos/año. Se publican artículos de revisión, artículos originales (biomédicos, clínicos y epidemiológicos), informes preliminares y cartas al editor, priorizando los temas relevantes de interés mundial como las enfermedades crónico-degenerativas (50\% corresponden a cáncer, enfermedades cardiovasculares, diabetes mellitus, enfermedades neurológicas y renales). En los números especiales se abordan enfermedades que representan importantes desafíos para los sistemas de salud mundial como la aterosclerosis, la leucemia infantil, el microbioma y la salud mental (Figura 1).

Los procesos editoriales de la revista igualmente han evolucionado. De inicio, todo el trabajo editorial se realizaba localmente en máquinas de escribir de la Coordinación de Investigación y se imprimía en imprentas del Instituto Mexicano del Seguro Social. A partir de 1998 se firmó un contrato con la casa editorial Elsevier para la edición, impresión y distribución mundial de la 


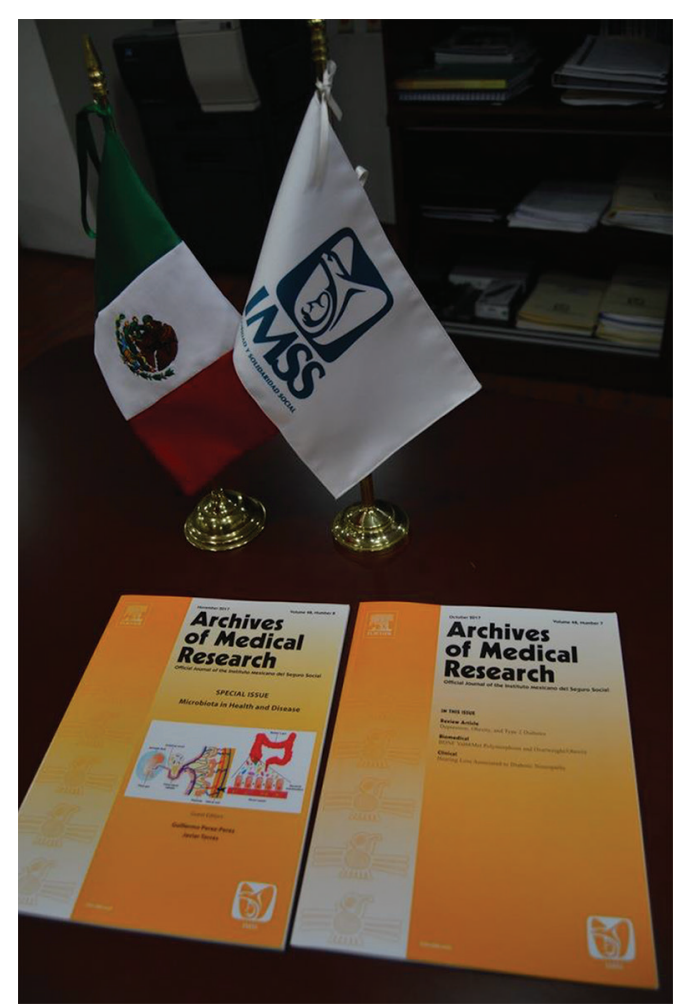

Figura 1. Portadas de Archives of Medical Research.

revista, quedando bajo responsabilidad del Instituto Mexicano del Seguro Social la selección de los manuscritos. A partir de entonces tomó el nombre Archives of Medical Research. Hasta 2018 se utilizó la plataforma Elsevier Editorial System para el manejo logístico de los manuscritos, y a partir de entonces se utiliza la plataforma EVISE (Elsevier), que facilita el manejo de estos, permite la detección de plagio, sugiere revisores de acuerdo con la temática principal y permite el acceso a Science Direct, entre otros.

La respuesta de la comunidad científica mexicana a este esfuerzo editorial fue inicialmente débil y en ocasiones de rechazo, pero a medida que la revista se ha posicionado internacionalmente, el flujo de manuscritos mexicanos se ha incrementado. En la actualidad, aproximadamente $30 \%$ de los artículos publicados son de procedencia mexicana. El éxito de la revista ha permitido que cada vez se reciban manuscritos de un mayor número de países, en promedio 778 manuscritos por año, provenientes de 54 países, entre los que destacan China, México, Estados Unidos, Irán, Brasil y Turquía.

Desde 2019, el número de manuscritos recibidos se ha incrementado, con un promedio de 80 por mes, y en 2020 de 119 por mes. La tasa de rechazo inicial es de $68 \%$ y $20 \%$ adicional es rechazado después de la revisión por pares (Figura 2). Todos los artículos publicados pasan por un estricto proceso de revisión por expertos temáticos, con un promedio de dos revisores por manuscrito. Dichos revisores provienen de 74 países; por su participación, todos obtienen como beneficio acceso a Scopus por un mes y descargan de la plataforma una constancia. Además, quienes realizan una destacada labor reciben por un año la revista impresa. El tiempo promedio desde el primer envío hasta la aceptación de un manuscrito es de 16.6 semanas y para su publicación en línea es de 19.4 semanas.

Hoy la revista es leída en todo el mundo, destacando que la mitad de las descargas de manuscritos se realiza en Estados Unidos, China, Reino Unido, Canadá y México. Nuestros artículos son citados por autores que publican en revistas de igual o mayor factor de impacto, como PLOS ONE, Oncotarget, Scientific Reports Nature, International Journal of Cardiology, Molecular Neurobiology y World Journal of Gastroenterology, entre otros.

El factor de impacto (Journal Citation Reports) de la revista se incrementó a partir de 1998, logrando en 2016 el máximo histórico de 2.718. A lo largo de los años se han tenido altas y bajas y en la última evaluación, el factor de impacto de JCR disminuyó a 1.895 (Figura 3), posicionando a la revista en el lugar 93 de 136 revistas internacionales en su categoría, pero continúa siendo la revista mexicana con mayor número de citas (3229) e índice $\mathrm{H}$ (69). En el ranking de Scopus CiteScore, Archives of Medical Research se encuentra en el percentil 92 de su categoría, con 2.1 (cuartil 1) y un porcentaje de citación de $65 \%$, ocupando el lugar 43 de 556 revistas en la categoría de medicina general (Figura 4); es la octava revista de la editorial Elsevier, solo detrás de Lancet (10.28), Lancet Global Health (4.51), Mayo Clinic Proceedings (4.03), Patient Education and Counseling (3), Sleep Medicine (2.78), Medical Clinics of North America (2.37) y Advances in Medical Sciences (2.1).

En septiembre de 2017, la revista recibió el premio Scimago-Conacyt, en reconocimiento como la primera revista científica mexicana clasificada en cuartil 1 (Figura 5).

A 50 años de su inicio, la revista afronta nuevos retos. Por un lado, la tendencia mundial a la ciencia abierta obliga a replantear el esquema de contrato con la casa editorial Elsevier para que la revista sea de acceso abierto, lo que permitirá, además, tener una mayor penetración y visibilidad en la comunidad 


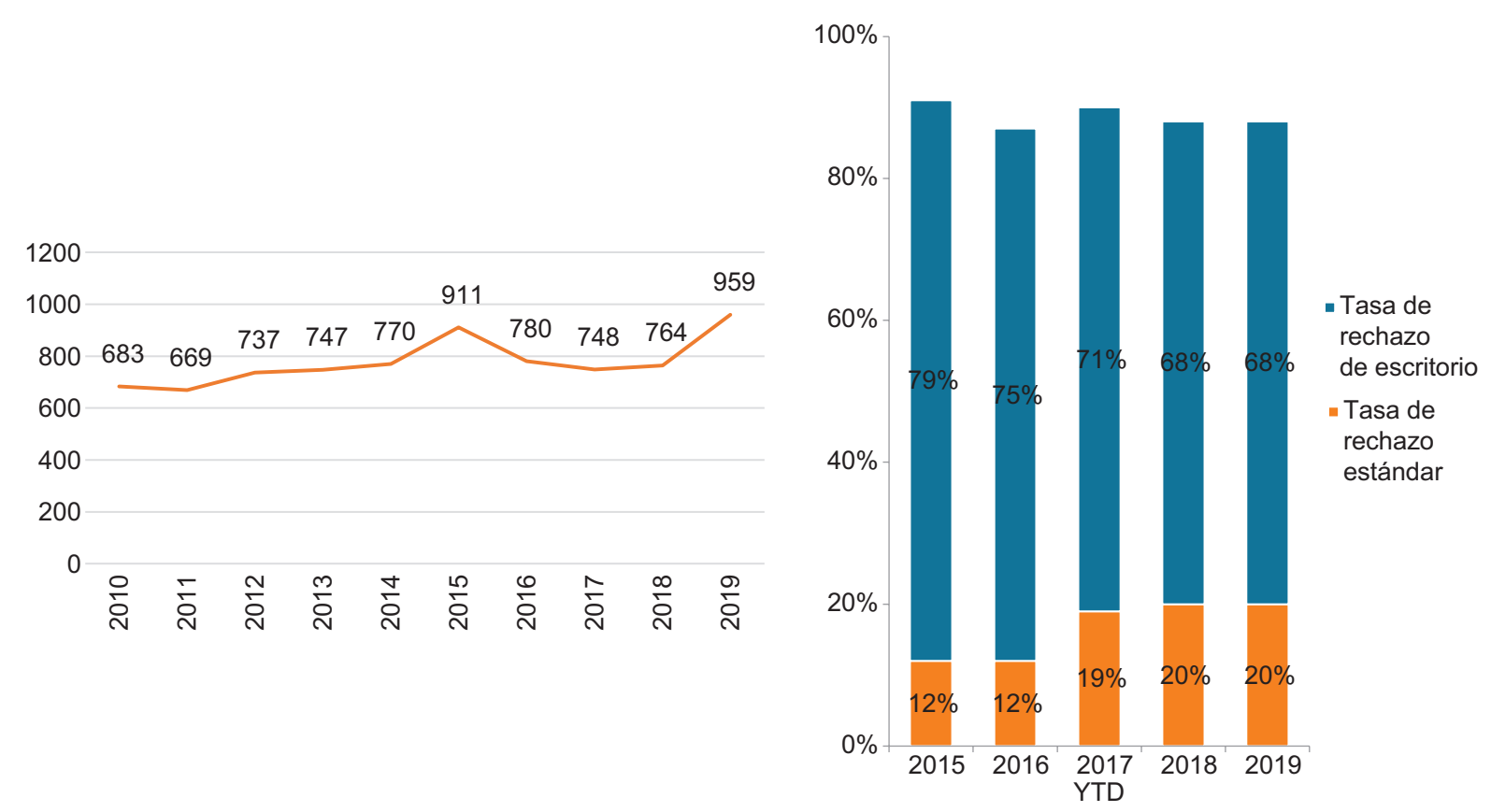

Figura 2. Manuscritos recibidos y tasa de rechazo por año, Archives of Medical Research.

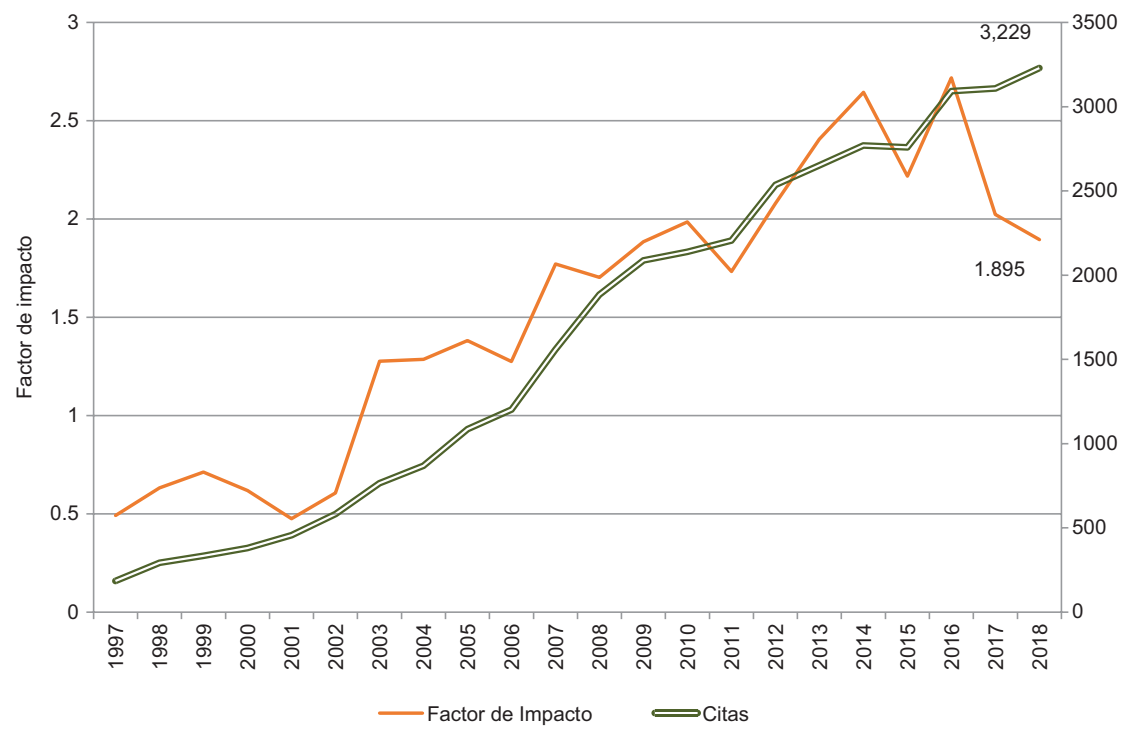

Figura 3. Factor de impacto de Archives of Medical Research (Journal Citation Reports) y número de citas por año.

científica mundial. En segundo lugar, la atracción de manuscritos de mayor calidad científica y la participación de revisores de talla internacional, que aporten realimentación constructiva a los autores para mejorar sus manuscritos. El tercer reto será modernizar y mejorar continuamente los procesos administrativos y disminuir los tiempos de publicación para ser más competitivos internacionalmente $\mathrm{y}$, por último, la capacitación continua del equipo editorial y la formación oportuna de cuadros de reemplazo.

Como puede verse en esta breve reseña, la organización, crecimiento y desarrollo de una revista científica en un país en desarrollo requiere planeación a mediano y largo plazo, de una inversión y apoyo 


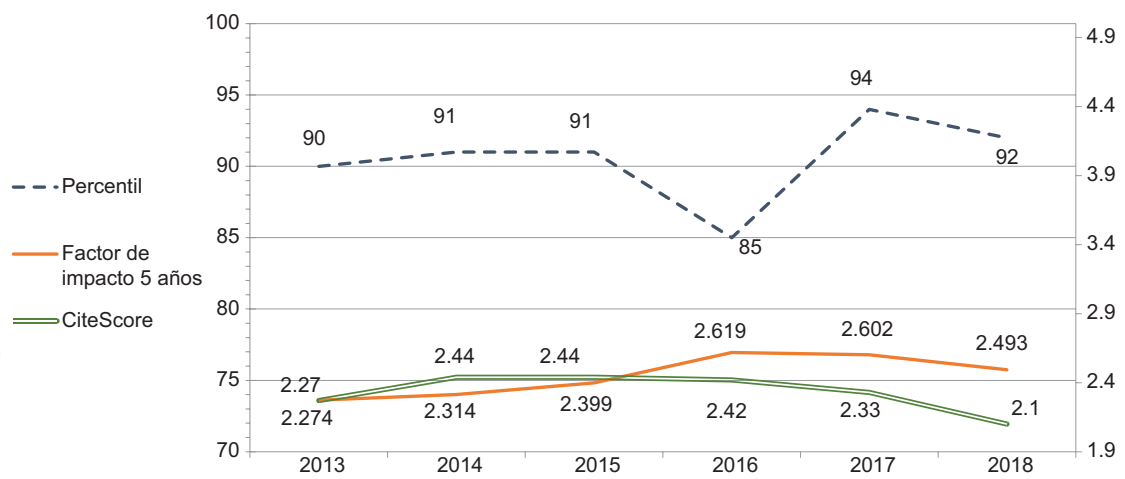

Figura 4. Scopus CiteScore, Archives of Medical Research.

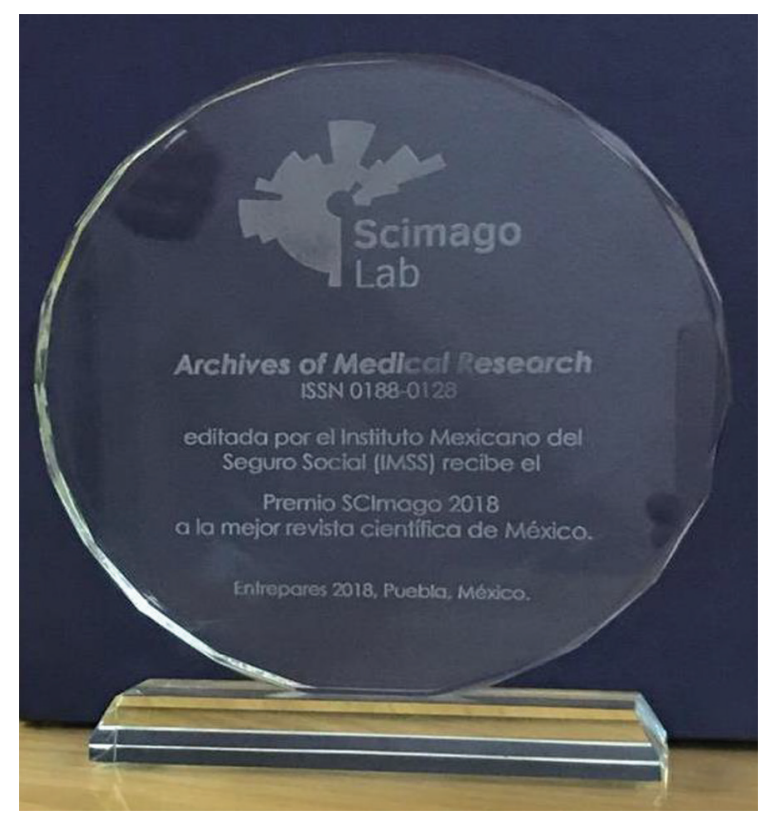

Figura 5. Reconocimiento Scimago-Conacyt a Archives of Medical Research.

institucional continuo y del compromiso y pasión de todos los que intervienen en el proceso.

\section{Revista de Investigación Clínica-Clinical and Translational Investigation ${ }^{1}$}

\section{Alfredo ulloA- aGuirre, moisés Selman-LAMA, LUIS OÑATE-OÑATE}

El primer número de Revista de Investigación Clínica salió a la luz en el año de 1948, dos años después de

1 *Dedicado al doctor José Báez Villaseñor, gran amigo, médico extraordinario y fundador de Revista de Investigación Clínica. la inauguración del Hospital de Enfermedades de la Nutrición (actualmente Instituto Nacional de Ciencias Médicas y Nutrición "Salvador Zubirán"), fundado por el doctor Salvador Zubirán Anchondo. Su primer editor y fundador fue el doctor José Báez Villaseñor (19481970), a quien siguieron el doctor Rubén Lisker (19711998, con el doctor Enrique Wolpert [1974-1988] y posteriormente el químico Alvar Loria [1989-1998] como coeditores) y el doctor Gerardo Gamba (19992014). Desde 2015, el editor en jefe es el doctor Alfredo Ulloa-Aguirre, con los doctores Moisés Selman y Luis Oñate como coeditores. Desde su fundación, la revista ha sido publicada ininterrumpidamente, al principio con una periodicidad trimestral y a partir de 1993 , bimensual.

Revista de Investigación Clínica ha evolucionado a lo largo de cuatro épocas, con distintas características particulares marcadas por sus diferentes editores en jefe. Inicialmente, durante su primera época, la mayoría de los artículos publicados (cerca de $90 \%$ ) provenía de autores del Hospital de Enfermedades de la Nutrición. En la segunda, conforme la revista fue posicionándose cada vez más entre la comunidad de investigadores clínicos nacionales como una publicación respetable en cuanto a la calidad de sus artículos, la contribución de los autores de su hospital fundador se redujo a la mitad, con la afluencia de artículos de investigadores provenientes de otras instituciones, la mayoría nacionales. El Science Citation Index, base de datos que actualmente es parte de la Web of Science perteneciente a la empresa Clarivate Analytics, fue el origen del factor o índice de impacto, como un reflejo de la citación y, en consecuencia, del impacto de los artículos publicados en las diferentes revistas científicas pertenecientes a esta base de datos; este factor de impacto es publicado anualmente 
por Journal Citation Reports, integrado a Web of Science. Fue precisamente durante esta segunda época que la RIC obtuvo su primer factor de impacto, el cual hasta 2018 osciló aproximadamente entre 0.25 y 0.5 (Figura 6). A finales de esta época, la revista se volvió gratuita a través de su versión en línea, sin interrumpir la publicación de la versión impresa.

La tercera época tuvo algunas características destacables:

- Se dio mayor énfasis a los artículos que fueran del interés de los lectores nacionales, al publicar predominantemente artículos de impacto local que potencialmente pudieran influir en las conductas diagnósticas o terapéuticas en México, así como en la formación de los médicos. La versión impresa se distribuyó en bibliotecas de casi todos los países de Latinoamérica.

- La revista se abrió a las contribuciones de los médicos residentes, para que pudieran iniciarse en la preparación y escritura de artículos, principalmente de investigación clínica.

- En 2008 pasó a ser la revista de los Institutos Nacionales de Salud de México, para aumentar las contribuciones de los médicos e investigadores de otros institutos.

- El factor de impacto se mantuvo alrededor de 0.45 , lamentablemente insuficiente para que la revista fuera tomada en cuenta por el Sistema Nacional de Investigadores (Figura 1A).

La cuarta y actual época de Revista de Investigación Clínica se inició en el 2015. El propósito del cambio fue que la Comisión Coordinadora de los Institutos Nacionales de Salud de la Secretaría de Salud le brindara apoyo tanto financiero como de difusión a la revista. Nuestro programa se basó fundamentalmente en la internacionalización de la revista con el objetivo de incrementar su factor de impacto y de esta forma volverla más atractiva para los investigadores nacionales e internacionales. Asimismo, esto le permitiría ajustarse a los criterios del Sistema Nacional de Investigadores para ser considerada en su lista de revistas científicas y ser tomada en cuenta para la evaluación de los artículos publicados por investigadores nacionales. Con estos propósitos se realizaron las siguientes modificaciones:

- El nombre de la revista cambió a Revista de Investigación Clínica-Clinical and Translational Investigation, para dar mayor prioridad a las contribuciones no solo originales sino con orientación a la medicina traslacional.
- Se cambió de compañía editorial, dándole esta responsabilidad a la editorial Permanyer (BarceIona, España).

- Se modificó sustancialmente el comité editorial y se amplió el tipo de artículos (revisiones en extenso, revisiones breves, comunicaciones rápidas, cartas de investigación, artículos originales y cartas al editor).

- Se cambió el idioma del contenido, de ser bilingüe (inglés o español) a ser totalmente en inglés, incluyendo su plataforma en línea (www.clinicalandtranslationalinvestigation.com) para el depósito de artículos, comunicación entre los editores, asignación de revisores, etcétera.

- Se limitó la impresión en papel, dando prioridad a la publicación en línea, de acceso libre.

- Se disminuyó considerablemente (casi en 50 \%), el número de artículos incluidos en cada número, publicando de seis a nueve artículos por número, programándose de la forma más expedita posible (máximo 30 días) las revisiones por pares y a 60 días el tiempo promedio desde que se recibe un artículo hasta que se acepta.

- Se modificó la portada para hacerla más atractiva a los lectores (Figura 7) y se eliminaron totalmente los anuncios de la industria farmacéutica.

Con estos cambios, en solo tres años (2015-2017) el factor de impacto se incrementó a 1.360 y en el periodo 2018-2019 a 1.513 (Figura 6), manteniéndose solo por debajo de Annals of Hepatology y Archives of Medical Research entre las revistas mexicanas. En 2019, el factor de impacto disminuyó a 1.192, para lo cual influyó de forma importante el retiro del apoyo financiero, de difusión y bibliográfico de la Comisión Coordinadora de los Institutos Nacionales de Salud a partir de enero de ese año. Sin embargo, en el CiteScore de Scopus, el índice de Revista de Investigación Clínica se incrementó de 1.29 a 2.7 (CiteScore considera las citas recibidas durante 20162019 a artículos y revisiones y las divide entre el número de documentos publicados durante este mismo periodo; en el caso de Revista de Investigación Clínica, el numerador fue de 437 y el denominador de 162) (Figura 6).

Además de la disminución en el número de artículos publicados en cada número, otro factor que ha contribuido al incremento del factor de impacto y del CiteScore ha sido la publicación periódica de números temáticos (cinco entre 2016 y 2019 y dos adicionales programados para 2020, incluyendo uno sobre COVID-19, número 3, mayo-junio). El número 


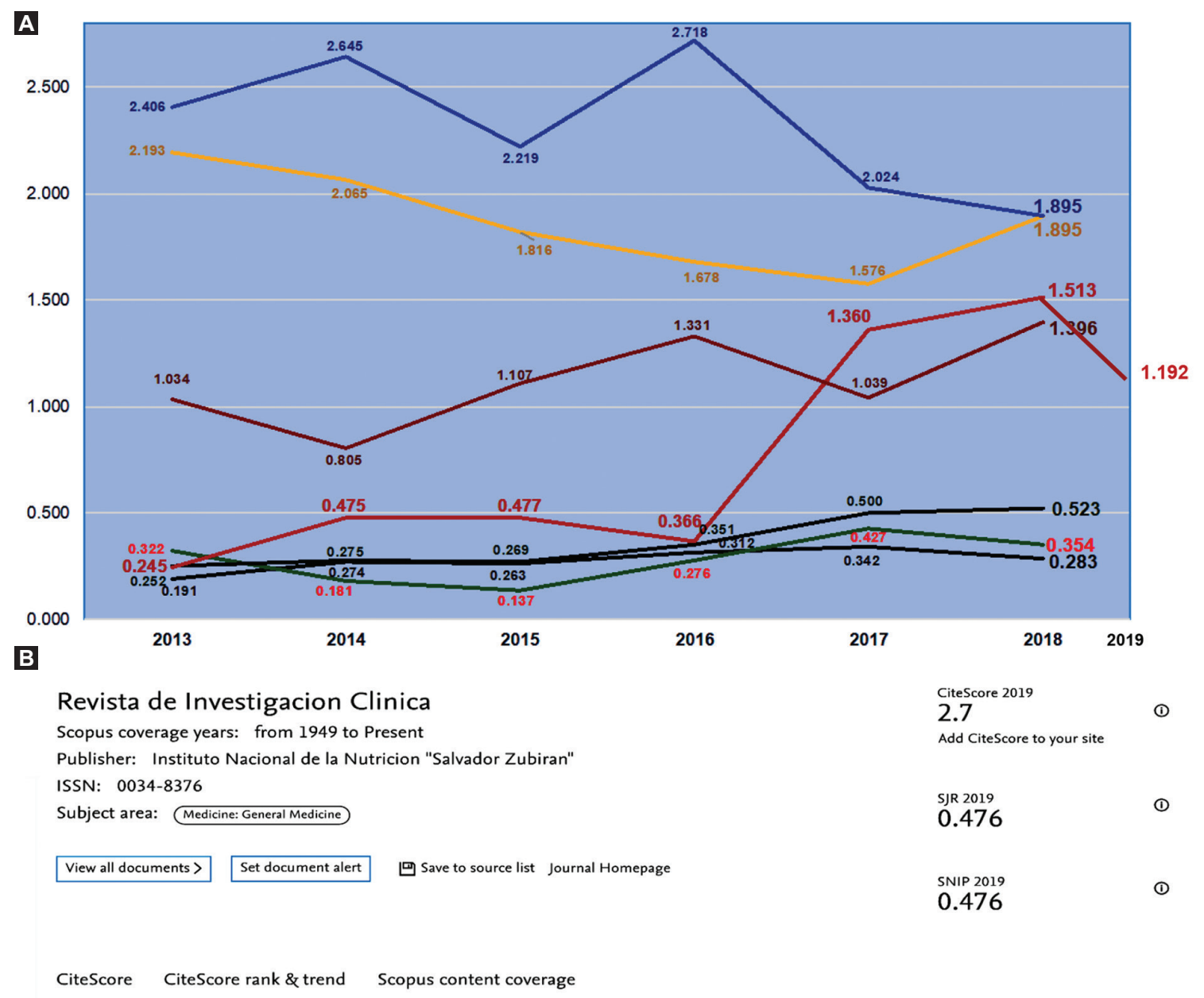

i Improved CiteScore methodology

Citescore 2019 counts the citations received in 2016-2019 to articles, reviews, conference papers, book chapters and data

papers published in 2016-2019, and divides this by the number of publications published in 2016-2019. Learn more >

CiteScore 2019
$2.7=\frac{437 \text { Citations } 2016-2019}{162 \text { Documents } 2016-2019}$
Calculated on 06 May, 2020

\section{CiteScoreTracker 2020 (1) \\ $1.5=\frac{195 \text { Citations to date }}{129 \text { Documents to date }}$}

Last updated on 10 June, 2020 . Updated monthly

CiteScore rank 2019 (1)

\begin{tabular}{lrr} 
Category & Rank & Percentile \\
\hline Medicine & & \\
$\llcorner$ General Medicine & $\# 87 / 529$ & 83rd
\end{tabular}

Figura 6. Factor de impacto y CiteScore (Elsevier) de Revista de Investigación Clínica-Clinical and Translational Investigation hasta 2019. A) Trayectoria del factor de impacto de acuerdo con el Journal Citation Reports (Web of Science). Nótese el rápido aumento a partir de 2017, de 0.245 en 2013 a 1.513 en 2018. B) CiteScore es otra medida del impacto de una revista académica, muestra el promedio anual de las citas de artículos recientes (2016-2019) publicados en la revista. CiteScore fue iniciado en 2016 por la editorial Elsevier, como una alternativa al factor de impacto. Los valores del factor de impacto y del CiteScore son similares, pero el segundo se basa en citas registradas en la base de datos Scopus durante los tres años previos, en lugar de los dos o cinco años que considera el Journal Citations Reports.

de usuarios durante 2018 y 2019 fue de 19225 y 25 155, respectivamente; al 31 de diciembre de 2019, el número de visitas al sitio en ese año fue de 61 047, en su mayoría de México ( 30\%), Estados Unidos $(\sim 14 \%)$, China ( 7\%), Brasil y España ( 5\% cada uno), entre otros. En 2019 se recibieron 229 artículos, 


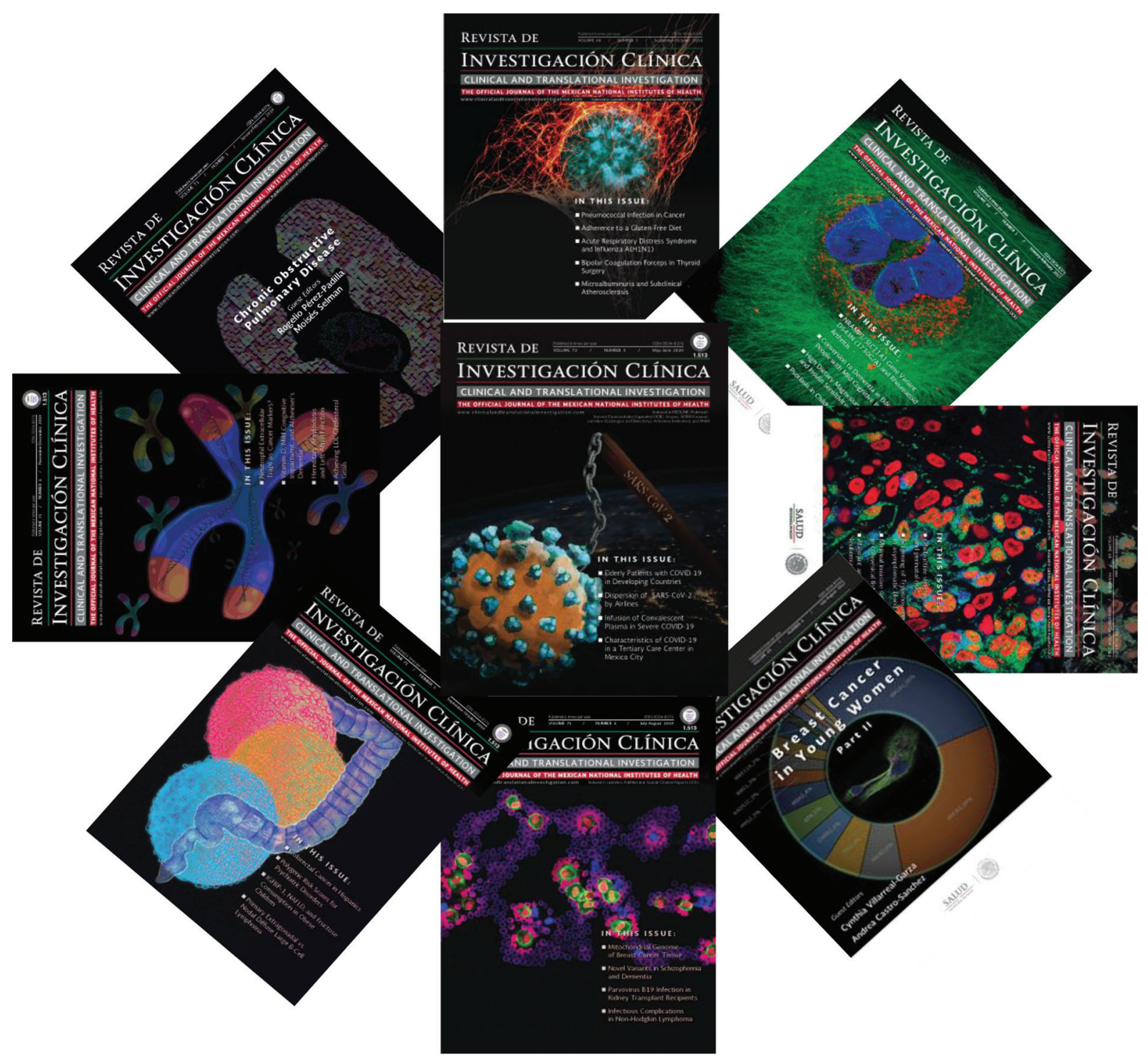

Figura 7. Algunas de las portadas de Revista de Investigación Clínica-Clinical and Translational Investigation, publicadas entre 2015 y 2020.

de los cuales $63.3 \%$ se rechazó para publicación. En la Tabla 1 se muestran algunos de los artículos de Revista de Investigación Clínica más leídos hasta 2019. Para 2018, ocupaba el lugar 102 (percentil 81) entre las 549 revistas de medicina general consideradas por el CiteScore de Scopus-Elsevier. Revista de Investigación Clínica (ISSN 0034-8376, eISSN 2564-8896) está actualmente indizada por Medline (Pubmed), Science Citation Index Expanded (Joint Committee on Intercollegiate Examinations), Scopus, SCRMCYT-Conacyt, Latindex (Catálogo y Directorio), Artemisa, Imbiomed y MIAR (Matriz de Información para el Análisis de Revista, Universitat de Barcelona, España).
Gaceta Médica de México, la fortaleza de la Academia Nacional de Medicina de México

\section{Alejandro tReViño- beCERRA}

Si dijera que Gaceta Médica de México, fundada en 1864, es la revista mexicana más antigua de nuestro país no faltaría a la verdad, pero lo haría si dijera que su publicación ha sido ininterrumpida, ya que en 1917 dejó de publicarse para reanudarse en 1919, según refiere la historiadora Martha Eugenia Rodríguez Pérez. Un siglo después, en 2019, la revista dejó de publicarse impresa, si bien generosamente la editorial Permanyer imprime tres ejemplares de cada número 
Tabla 1. Artículos publicados en Revista de Investigación Clínica-Clinical and Translational Investigation más leídos durante el periodo 2016-2019

\begin{tabular}{|c|c|c|}
\hline $\begin{array}{l}\text { Artículo } \\
\text { ID }\end{array}$ & Título & $\begin{array}{l}\text { Número de } \\
\text { lecturas }\end{array}$ \\
\hline 187 & Familial combined hyperlipidemia: current knowledge, perspectives, and controversies & 844 \\
\hline 171 & $\begin{array}{l}\text { Nutritional assessment tools for the identification of malnutrition and nutritional risk associated with cancer } \\
\text { treatment }\end{array}$ & 739 \\
\hline 198 & Smoking cessation treatments: currrent psychological and pharmacological options & 592 \\
\hline 140 & $\begin{array}{l}\text { Practical approach to the evaluation and management of rheumatoid arthritis-interstitial lung disease on its } \\
\text { proven and hypothetical mechanisms }\end{array}$ & 514 \\
\hline 73 & Biology of healthy aging and longevity & 453 \\
\hline 174 & Use of functional foods and oral supplements as adjuvants un cancer treatment & 447 \\
\hline 83 & The role of immunosenescence in the development of age-related diseases & 391 \\
\hline 80 & Frailty and sarcopenia: the new geriatriac giants & 330 \\
\hline 213 & $\begin{array}{l}\text { I. The role of research ethics committees in observational studies: epidemiological registries, case reports, } \\
\text { interviews, and retrospective studies }\end{array}$ & 329 \\
\hline 201 & Role of genetic susceptibility in nicotine addiction and chronic obstructive pulmonary diseases & 315 \\
\hline
\end{tabular}

con fines de mantener la colección completa en la biblioteca y en los archivos históricos.

En más de siglo y medio, antes que nosotros hubo 29 editores y si se suman los coeditores adjuntos agregaremos otros 59, casi todos académicos. Los tres editores con más tiempo en el cargo han sido Miguel Jiménez, Luis Benítez Bribiesca y don Silvestre Frenk, a quien perdimos físicamente este año y que fue editor de 1967 a 1984, la mayor parte de los años, como editor único. Otra gran pérdida fue la de mi amigo y mentor, el doctor Francisco Olvera Esnaurrízar, editor asociado de Gaceta Médica de México en el periodo 1960-1961, quien después dio inicio al desarrollo de Revista Médica del Instituto Mexicano del Seguro Social.

Colaboré con dos competentes editores: con el doctor Francisco Pérez del Rincón auxilié como editor asociado por dos años y después con el coordinador de este simposio, el doctor Alfredo Ulloa Aguirre (con el doctor Fernando Larrea como coeditor), colaboré como tesorero cuando el presidente en turno de la Academia Nacional de Medicina, el doctor Emilio García Procel, formó un comité administrativo para apoyar a los editores.

En la década de 1960 llaman la atención dos modalidades temporales: por un lado, la participación de hasta seis académicos en la función editorial, quienes se dividían de tres a cuatro números de determinado año; por otro, la renovación escalonada del grupo editorial, en la que el coeditor ascendía a editor en una nueva directiva.

La idea de retomar un apoyo administrativo y técnico la implanté en 2017, para lo cual invitamos al doctor Francisco Espinosa Larrañaga para desempeñarse como editor ejecutivo con base a su experiencia. Considero que se requiere la participación de un editor ejecutivo con pago de honorarios por las horas de trabajo que debe dedicar a cada número y el trabajo constante con el editor y coeditores.

Son coeditores actualmente, Miguel López Cruz, investigador nacional con reconocimiento internacional, y Martha Eugenia Rodríguez Pérez, destacada historiadora de la medicina $y$, por cierto, primera mujer en pertenecer al cuerpo de editores de Gaceta Médica de México; trabaja como asistente Alma Morales, con quien hemos conformado un equipo amistoso, disímbolo, trabajador y exitoso. Nosotros sucedimos a los doctores Alberto Lifshitz, José Halabe y Manuel Ramiro. También acordamos proyectos con el ingeniero Víctor Torrecillas, traductor oficial, Elizabeth Gallardo, el propio señor Ricardo Permanyer, el director comercial Frank García y Gabriela Ramírez. Incluimos, además, a Miguel Ángel Vázquez como ejecutivo de sistemas digitales y a las contadoras Paola Valencia y Gabriela Nava, para el apoyo contable. 
En mi experiencia, entre el cuerpo directivo de la Academia y el grupo editorial se pueden establecer tres tipos de relación: de dependencia, independencia y corresponsabilidad, esta última es la más útil, pero también la más difícil de lograr.

En la numeraria de Gaceta destacamos que estamos al día en la aceptación o rechazo de trabajos. En tres años y medio se recibieron 1558 trabajos (de enero de 2017 a 1 de junio de 2020). Para facilitar el trabajo y seguimiento se desarrollaron guías de trabajo, una para la aceptación o rechazo y otra para filtrar y ayudar a la revisión e identificación de revisores.

La mayor debilidad de Gaceta Médica de México era la poca y tardía respuesta de los revisores; en los últimos meses esto ha mejorado por la mayor comunicación y reconocimiento a los revisores; sin embargo, es recomendable que se aumente el número de revisores y que estos realicen su función con prontitud. También creo que se puede cambiar de nombre de revisor, ya que el término ahuyenta a los pares o bien los estimula a hacer unos análisis exhaustivos del trabajo. Además, si la revisión es por pares, en ocasiones un buen manuscrito elaborado por médicos jóvenes llega al escritorio de un académico y se establece una circunstancia impar, es decir, un aprendiz ante un experto o maestro.

Consideramos que en estos casi cuatro años, Gaceta Médica de México ha tenido avances no solo en el cambio de portada. En 2017 editamos los seis números regulares, un número extraordinario solo en versión electrónica con 38 artículos rezagados, un suplemento con los trabajos de ingreso de los académicos del año correspondiente y otro patrocinado, es decir, nueve números en el primer año. Con dos suplementos de un total de 10 que están en elaboración para el segundo semestre, se publicarán un total de dos suplementos y con los ingresos de los patrocinadores se tiene previsto pagar al traductor los últimos números de este año.

Los integrantes del consejo y del comité editorial participan más y tienen mayor visibilidad, y se ha establecido con ellos comunicación para asuntos formales de la revista; con los integrantes del comité, para alentarlos y agradecerles su participación. Suprimimos secciones para dar uniformidad a los contenidos: editorial, artículos originales, temas de revisión, comunicaciones breves, cartas al editor y una pequeña sección sobre la vida de la academia. No siempre contamos con un simposio para publicar los presentados en las sesiones de la academia.
Esto nos lleva a reflexionar sobre qué revista debe ser Gaceta: para investigadores y pretender aumentar el factor de impacto, el más reciente de 0.283 , e intentar un estudio bibliométrico para tener otros parámetros de calidad, como el CiteScore (0.342) de Scimago Journal \& Country Rank y el índice H (de 17). Pocos académicos publican en Gaceta, de hacerlo, se elevaría el factor de impacto.

Los integrantes del consejo editorial, las próximas directivas y los propios académicos debemos precisar y definir ¿qué revista debe ser Gaceta Médica de México? Aunque yo la dejaría tal y como está: una buscada revista mexicana de calidad, impresa en español y en línea traducida al inglés, abierta a todas las áreas del conocimiento médico, al día, útil, leída, indexada, interesante e internacional. De ahí que a partir de este año, Gaceta Médica de México lleva como subtítulo Medicina contemporánea. Continuará publicando los mejores trabajos que reciba. Un despacho especializado en traducciones comentó que la revista es muy compleja y difícil porque su contenido es amplísimo y varía la temática de número a número.

No puedo omitir que en estos dos últimos años Gaceta Médica de México se ha visto afectada por la reducción presupuestal y en 2019 se suprimió la forma impresa. Al respecto, dos editores emitieron significativas opiniones. El doctor Silvestre Frenk envió un correo electrónico en el que expresaba su sentir:

Me parece que incorporarse a la era digital es una consecuencia inevitable de los tiempos actuales, incluida la Gaceta Médica de México. De modo que no me queda más que decir precisamente eso: NI MODO.

El doctor Francisco Olvera Esnaurrizar, comentó que "no podía desaparecer la revista impresa y que bien se podría pedir a cada académico una pequeña contribución o encontrar un mecenas para sostenerla".

Por las mismas razones económicas, este año nos pidió la mesa directiva que a los potenciales autores se les solicitara el trabajo electrónico en inglés, para no pagar la traducción con el interés "cientista" y "eficientista" a Gaceta Médica de México.

Por otro lado, el número 4 de este año aparecieron 10 trabajos sobre el COVID-19, de los más de 40 que llegaron a la mesa editorial entre febrero y mayo del año en curso, lo que sumado a los publicados en los números 2, 3, 5 da un total de 25 trabajos sobre este tema. Lo anterior indica la posición que ocupa la Gaceta en la actualidad. 
Una reflexión: el edificio que ocupa la Academia Nacional de Medicina de México es la sede de tres de las revistas que participan en este simposio.

- Archives of Medical Research.

- Cirugía y Cirujanos.

- Gaceta Medica de México.

Y de dos más que no están participando en este simposio, Revista Médica del Instituto Mexicano del Seguro Social y Revista de Enfermería del Instituto Mexicano del Seguro Social.

Las tres participantes tienen similitudes y diferencias, pero enfrentan, entre otros, problemas económicos; si fuéramos emprendedores trataríamos de disminuir las debilidades y aprovechar las oportunidades para garantizar nuestras ediciones a corto y mediano plazo, en una especie de consorcio.

Por otro lado, hay muchos trabajos de calidad que no son aceptados, situación que sucede también en Cirugía y Cirujanos, lo que nos demuestra que se requiere una nueva revista médica más sencilla, más frecuente, con mayor circulación, alejada de la bibliometría, autofinanciable y útil para nuestros médicos y lectores.

Finalmente, de los documentos publicados sobre "el mundo después de la pandemia COVID-19" quiero citar el siguiente concepto:

Las personas necesitan confiar en las autoridades públicas, la ciencia y los medios de comunicación. La Academia Nacional de Medicina es una autoridad en la medicina mexicana y su Gaceta, con sus publicaciones médicas científicas, la convierte en un extraordinario y accesible medio de comunicación médica.

Gaceta ha estado vigente en tres siglos, de ahí su fortaleza sustentada en la dedicación, altruismo y producción intelectual médica. Espero que la revista continúe siendo la mayor fortaleza de la Academia Nacional de Medicina de México y resista las adversidades externas e internas.

\section{Salud Pública de México}

\section{Carlos oropeza-ABÚNDEZ}

Salud Pública de México se editó por primera vez en 1959, como órgano de difusión de la entonces Secretaría de Salubridad y Asistencia, institución rectora del Estado mexicano en el ramo de la salud. Nació con el propósito de abordar temas no solo de medicina general, sino también de epidemiología, saneamiento, administración y legislación sanitaria, entre otros, así como de difundir notas sobre la salud pública en el ámbito nacional y el internacional. ${ }^{5}$ Es preciso señalar, no obstante, que la revista es producto de la transformación histórica y la amalgama de distintos órganos informativos oficiales en la materia. El antecedente primordial en ese sentido es el Boletín del Consejo Superior de Salubridad (que salió a la luz en 1880), considerado como el primer impreso mexicano destinado a abordar temas de salud pública. ${ }^{5,6}$ Más tarde le siguieron otras publicaciones, de acuerdo con la evolución que fueron mostrando las distintas instancias gubernamentales creadas para atender la salud poblacional.

A mediados de la década de 1960, ya constituida como revista, Salud Pública de México absorbió al Boletín Epidemiológico, editado por primera vez en 1937 como medio de difusión de la Oficina General de Epidemiología y Profilaxis de las Enfermedades Tropicales. Tiempo después, en 1977, hizo lo mismo con Revista del Instituto de Salubridad y Enfermedades Tropicales, a raíz de lo cual amplió su quehacer, no solo en la vigilancia epidemiológica y como órgano de difusión de las actividades de la Secretaría de Salud y Asistencia, sino que comenzó a adquirir un matiz científico. ${ }^{5}$

Sin embargo, son tres los hechos que terminaron por imprimir un carácter académico a Salud Pública de México: el primero de ellos tiene que ver con que en 1979 las notas informativas de la Secretaría de Salud y Asistencia comenzaron a publicarse en un boletín institucional específico para ello y que la difusión del informe epidemiológico anual quedó bajo la responsabilidad del Boletín de la Dirección General de Epidemiología. El segundo está relacionado con la creación del Centro de Investigaciones en Salud Pública, de lo cual se derivó que en 1985, la revista, entonces a cargo de la Escuela de Salud Pública de México, incluyera en su contenido una sección editada por dicho centro. El tercero tiene que ver con la constitución, en 1987, del Instituto Nacional de Salud Pública; a raíz de ello, Salud Pública de México dejó de cumplir su papel como órgano oficial de la Secretaría de Salud y quedó bajo la conducción del Instituto. Este último acontecimiento marcó la preparación de una nueva época para la revista, definida por el fortalecimiento de su contenido científico mediante la ampliación de su comité editorial, la inclusión de un mayor número de investigaciones originales, la formalización del proceso de arbitraje y el apego a normas editoriales internacionales como los 
Requisitos uniformes para preparar los manuscritos enviados a las revistas biomédicas. ${ }^{7}$

A partir de 1988, la revista se publica siguiendo las pautas de una nueva época y va extendiendo su incorporación en los índices y bases de datos de mayor presencia internacional. Estando ya inscrita en algunos de ellos, en 1993, por ejemplo, logró su aceptación en la versión Social and Behavioral Sciences de Current Contents. Al siguiente año fue certificada por el Índice de Revistas Mexicanas de Investigación Científica y Tecnológica del Consejo Nacional de Ciencia y Tecnología (Conacyt) y en 1997, a invitación expresa del Centro Latinoamericano de Información en Ciencias de la Salud (BIREME) de la Organización Panamericana de la Salud-Organización Mundial de la Salud, la revista fue incorporada a la iniciativa SciELO Salud Pública, de la cual forma parte hasta el momento (Tabla 2).

Las distinciones obtenidas por Salud Pública de México son diversas: en 2014, el Conacyt reconoció a sus editores por el trabajo desempeñado al frente de la revista. Un año después, este mismo organismo otorgó a la publicación un premio destacándola como una "revista mexicana multidisciplinaria con alto posicionamiento", y en 2017 la calificó como "la mejor revista científica de México" en todas las áreas del conocimiento. ${ }^{8}$

El factor de impacto, creado por el Institute for Scientific Information en 1975 y actualmente publicado por la empresa Clarivate Analytics, también es motivo de atención por parte del cuerpo editorial de Salud Pública de México. A partir de la aceptación de la revista en el Social Sciences Citation Index, la puntuación que ha obtenido en ese indicador se ha mantenido en ascenso a lo largo de más 20 años (Figura 8).

Para permanecer vigente en el ámbito de la comunicación científica, Salud Pública de México, al igual que las principales revistas internacionales, da seguimiento y se actualiza conforme a las mejores prácticas editoriales: operación a través de un sistema de sometimiento y gestión en línea (Open Journal Systems, de código abierto), uso de identificadores digitales (DOI) y versiones de interoperabilidad (XML), adopción de licencias de acceso abierto Creative Commons, difusión oportuna a través de publicación ahead of print y la adhesión a iniciativas como la San Francisco Declaration on Research Assessment (DORA) y la Initiative for Open Citations.

En cuanto a su contenido, el cual se encuentra íntegramente digitalizado y con acceso abierto desde el primer número de 1959, Salud Pública de México
Tabla 2. Índices y bases de datos en los que se encuentra inscrita Salud Pública de México, 2020

Abstracts on Hygiene and Communicable Diseases

Biological Abstracts

BIOSIS Previews

Current Contents/Social and Behavioral Sciences

Directory of Open Access Journals (DOAJ)

EMBASE/Excerpta Medica

Essential Science Indicators

Global Health/CAB Abstracts

Índice de Revistas de Educación Superior e Investigación Educativa (IRESIE)

Latindex

LILACS

MedicLatina

Periódica

RedALyC

SciELO Citation Index

Scientific Electronic Library Online (SciELO)

Scopus (Elsevier)

Sistema de Clasificación de Revistas Mexicanas Ciencia y Tecnología CONACYT

Social Sciences Citation Index (Web of Science Core Collection | Clarivate)

prioriza los resultados de investigación que atañen a la salud poblacional en el mundo, pero a su vez fortalece el análisis de los problemas sanitarios relevantes en México:9,10 enfermedades crónicas, lesiones, salud mental, reforma del sistema de salud, aspectos relacionados con la sociología y la antropología médicas, la economía de la salud, la administración hospitalaria y la definición de políticas sanitarias. Se privilegian los desarrollos instrumentales más avanzados en el campo de la epidemiología, incluyendo trabajos de excelencia en las áreas de nutrición, salud reproductiva y salud ambiental. Las bases biológicas de la salud pública tienen presencia mediante el análisis de temas relacionados con la investigación experimental en los campos de la resistencia bacteriana, la inmunidad y la elaboración de vacunas, entre otros. Las tendencias de las enfermedades emergentes y reemergentes son también tema permanente en las páginas de la revista. 


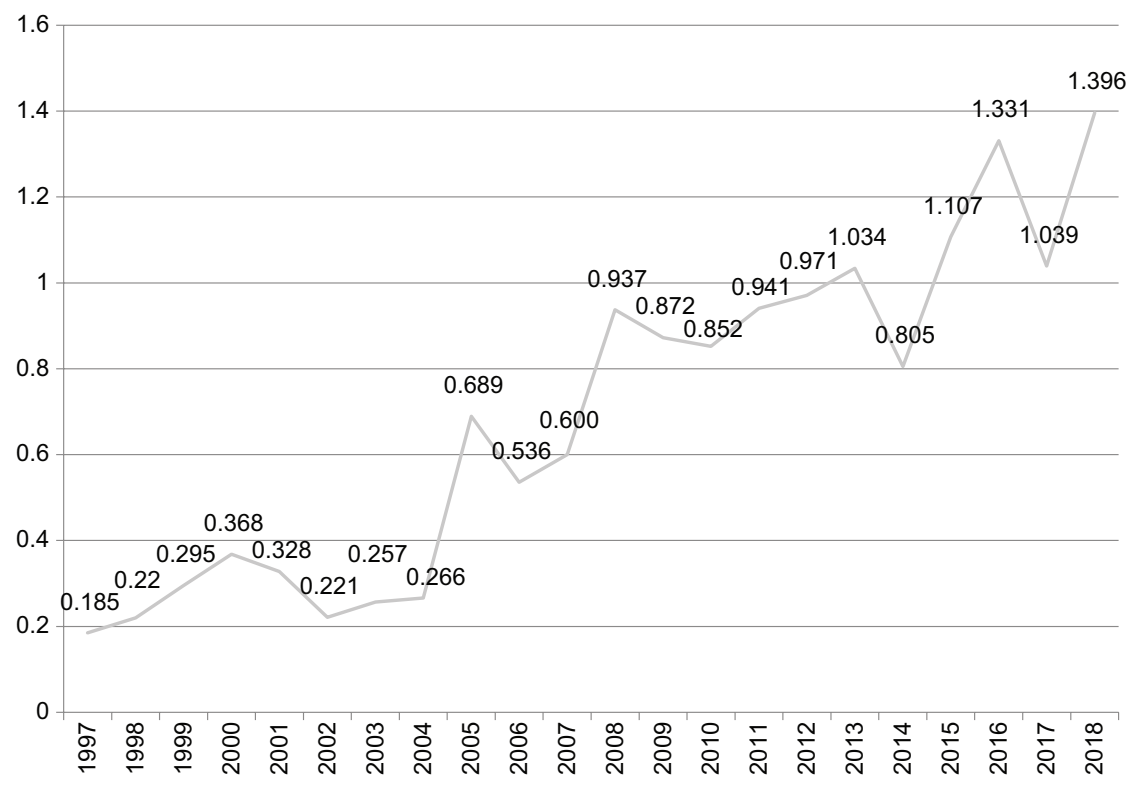

Figura 8. Factor de impacto de Salud Pública de México, 1997-2018.

La publicación y la visibilidad expedita de los resultados de investigación sobre las grandes amenazas que hoy vulneran la salud de la población en el planeta (como la pandemia de COVID-19, producida por el virus SARSCoV-2) son aspectos de alta prioridad para Salud Pública de México. ${ }^{11,12}$ La búsqueda de nuevos caminos y paradigmas para enfrentar este tipo de coyunturas son, sin duda, uno de los grandes retos a los que deben responder todas las revistas científicas de la región.

Con independencia editorial y sin la tutela o participación de consorcios comerciales, Salud Pública de México ratifica que la publicación de excelencia para contribuir a mejorar las condiciones de salud de la población, el acceso abierto al conocimiento como un bien público y el apego a la ética de la comunicación científica seguirán siendo los pilares de su identidad y política editorial.

\section{Cirugía y Cirujanos}

\section{Sergio Sobrino-cossío y PEDRO GUTIÉRREZ- CASTRELLÓN}

La actualización médica requiere la búsqueda del conocimiento. Las estrategias de prevención, comportamiento epidemiológico de las enfermedades, diagnóstico precoz, tratamiento oportuno, manejo de complicaciones y la toma de decisiones sanitarias están sustentadas en la evidencia científica. ${ }^{13}$
En un mundo globalizado necesitamos tener acceso a las principales revistas médicas especializadas. Existen revistas especializadas en un área, por ejemplo, en oncología, cardiología, hematología, etcétera, y otras que abarcan muchas. Al final, el reto de todas es la generación de conocimiento (logos) de alta calidad, fácil comprensión, aceptación (pathos) y credibilidad (ethos).

Desde su creación en 1933, Cirugía y Cirujanos ha desempeñado de forma altamente eficiente su relevante misión de ser el órgano de difusión científica de la Academia Mexicana de Cirugía, órgano consultivo del Gobierno Federal en materia de salud y política social y asesor del Consejo de Salubridad General de México. La revista se encuentra en diversos índices bibliohemerográficos como Index Médicus, Excerpta Médica e Índice Latinoamericano de Revistas Científicas, entre otros.

El objetivo de Cirugía y Cirujanos es publicar trabajos originales del amplio campo de la medicina, así como proporcionar información actualizada y relevante para el área de la salud nacional. Nuestra revista es bilingüe (español/inglés), bimestral, de acceso abierto y tiene un proceso riguroso de revisión por pares. El contenido incluye editoriales, artículos originales, casos clínicos, artículos de revisión (interés general) y cartas al editor.

Cirugía y cirujanos está regida por la ética editorial que incluye un código de buenas prácticas, la protección de 
personas y animales, confidencialidad, privacidad, financiación, autoría (Requisitos uniformes para preparar los manuscritos enviados a las revistas biomédicas) y declaración de conflicto de intereses.

La credibilidad de las revistas se debe:

- Al factor de impacto, que se refiere al número de veces que se ha citado un artículo promedio en una revista para determinado año, dividido entre el número total de artículos publicados en los dos años anteriores.

- Al proceso riguroso de revisión por pares (expertos en contenido) con el que se evalúa si un manuscrito es factible, interesante, novedoso, con metodología ética y relevante.

El proceso de revisión por pares incluye varios pasos:

1. Revisión por la oficina editorial.

2. Revisión (editor jefe).

3. Asignación de un editor responsable.

4. Invitación de revisores.

5. Revisión por pares.

6. Evaluación de resultados de las revisiones por parte de la revista

7. Comunicación de la decisión final al autor (aceptado/rechazado)

8. Doble revisión de la gramática, estilo y referencias en la versión final (empresa editorial).

9. Pruebas maquetadas del artículo antes de la publicación (autorización final del autor). ${ }^{14,15}$

En la Tabla 3 se muestra el comportamiento del factor de impacto de Cirugía y Cirujanos en los últimos años. Un alto factor indicará que la publicación es altamente influyente en la comunidad médica; es un indicador del impacto del manuscrito de un autor concreto. Una revista con factor de impacto de tres significará, en promedio, que los artículos publicados en los últimos dos años han sido citados tres veces.

El rendimiento de una investigación y el seguimiento de las tendencias científicas pueden ser evaluados mediante un análisis cuantitativo.

Mientras mayor es el factor de impacto de una revista, menor será el porcentaje de aceptación de un manuscrito sometido para publicación (en Lancet solo es de $5 \%$ ). El factor de impacto fue 42.315, 39.207, 30.0, 16.3 y 16.104 para Nature (2014), Lancet (2013), JAMA, British Medical Journal (2014) y Annals of Internal Medicine (2014), respectivamente. Sin embargo, el número de citaciones no traduce la calidad metodológica.

Una enorme tarea de los editores ante la gran avalancha de artículos regidos por la moda es detectar el fraude científico y la duplicación de artículos. El físico Alan Sokal, después de publicar en 1996 un sofisticado artículo (Transgressing the boundaries toeard a transformative hermeneutics of quantum gravity), expuso la falta de rigurosidad y de evaluación del cuerpo de editores de la prestigiosa revista Social Text. ${ }^{16}$ Sokal quiso comprobar que una revista de humanidades "publicará un artículo plagado de sin sentidos, siempre y cuando: a) suene bien; y b) apoye los prejuicios ideológicos de los editores (contra las ciencias empíricas)". Concluyó que la objetividad es una convención social después de denunciar su parodia.

En 2002 ocurrió otro escándalo. Los hermanos Bogdanov, para evitar la revisión por pares, publicaron teorías absurdas y sin sentido en prestigiosas revistas científicas, que después fueron calificadas como pseudociencia..$^{17}$ Otro fraude científico en las revistas Nature y Science fue protagonizado en 2002 por el físico Jan Hendrik Schön. ${ }^{18}$ Uno más fue la disputa por la paternidad del aislamiento del VIH entre Montagnier, que publicó en Science su descubrimiento, y Gallo. ${ }^{19}$

Recientemente tenemos el gran escándalo de los datos falsos contra la hidroxicloroquina que involucró al New England Journal of Medicine y a Lancet a través de una empresa fantasma, por lo que ambas revistas se retractaron sobre los riesgos del fármaco, relacionados con problemas cardiacos graves y con un incremento del riesgo de muerte en pacientes con COVID-19. ${ }^{20}$

Por todo lo anterior, nuestro cuerpo de editores ha iniciado una reingeniería de procesos en la revista, entre los que destacan la implementación de un proceso de evaluación de propuestas de publicación apegado a las necesidades actuales y la invitación a formar parte de la plantilla de revisores a expertos en metodología de la investigación, medicina basada en la evidencia y el desarrollo de revisiones sistemáticas y guías de práctica clínica.

\section{Salud Mental}

\section{HÉCTOR ESQUIVIAS- ZAVALA}

Salud Mental es la publicación oficial del Instituto Nacional de Psiquiatría "Ramón de la Fuente Muñiz", la cual se edita desde agosto de 1977. Se ha mantenido de forma ininterrumpida desde su fundación y tiene una periodicidad bimestral. De acuerdo con las buenas prácticas de la publicación científica, los manuscritos recibidos son inicialmente dictaminados por un comité 


\section{Documentos publicados por año}

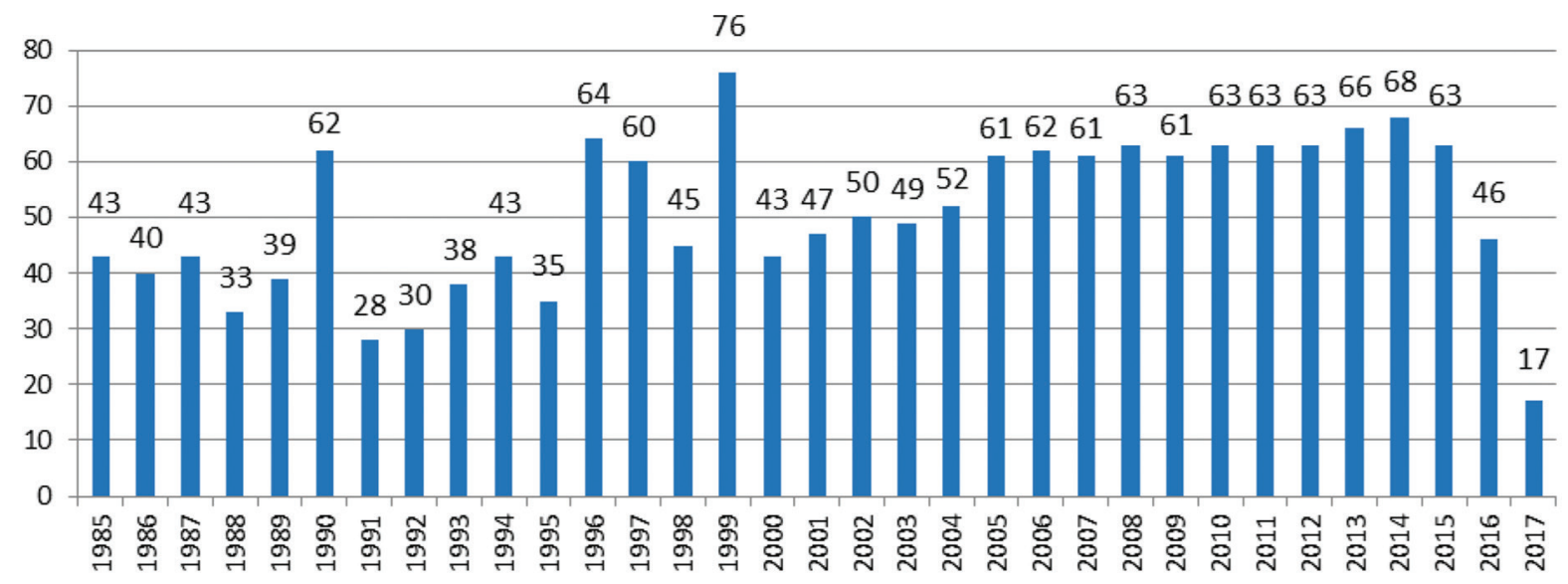

Citas a la revista Salud Mental

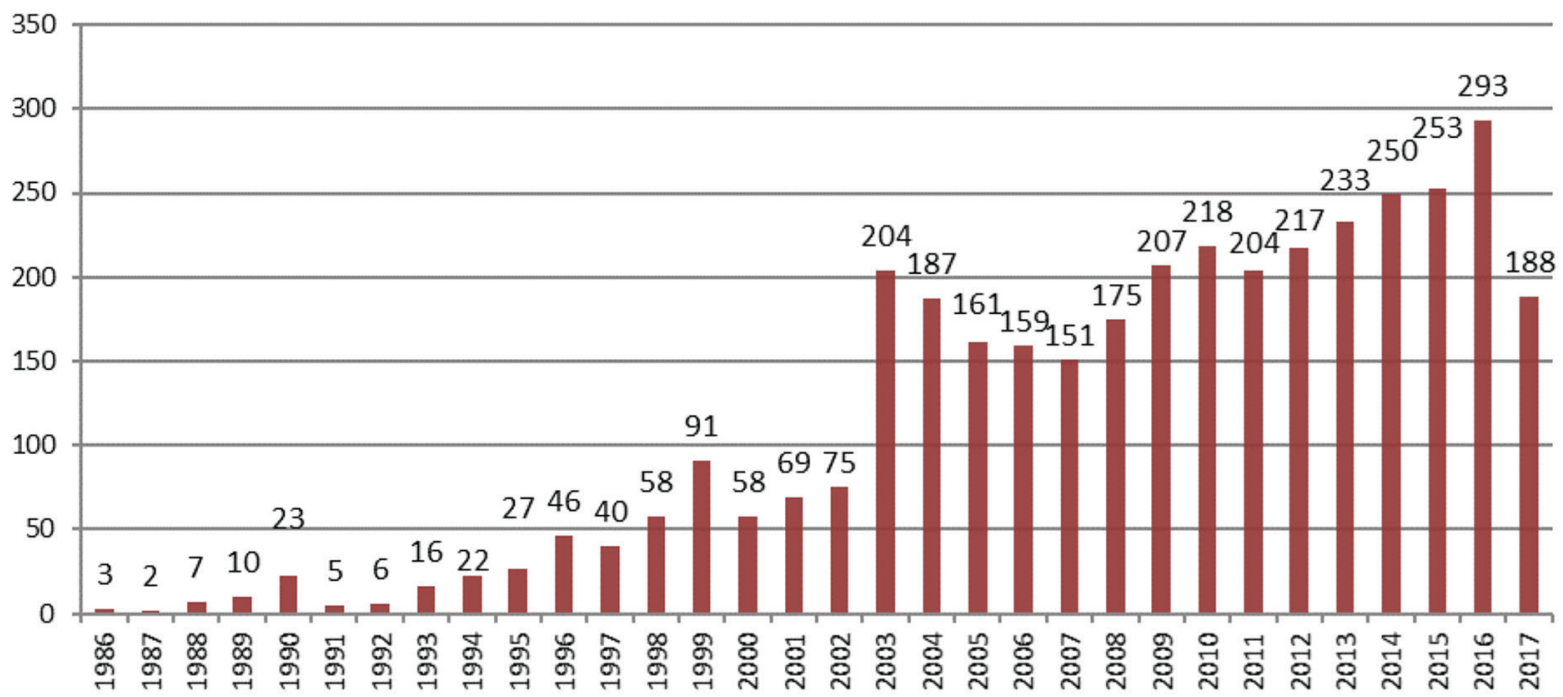

Figura 9. Análisis de producción documental 1985-2017 y número de citas 1986-2017, Salud Mental.

de revisión interno; los documentos aprobados posteriormente son arbitrados en un proceso doble ciego por expertos dictaminadores en los distintos temas. La revista publica números monotemáticos sobre temas relevantes para la comunidad científica como obesidad y salud mental, adicciones y próximamente publicará fascículos monotemáticos sobre el impacto de COVID-19 en la salud mental y salud mental laboral.

Salud Mental se encuentra indexada en Social Science Citation Index de Web of Science, Scopus, Academic Search Premier, Journal Citation Report, SciELO, PsycINFO, IMBIOMED, RedALyC, LILACS, BIREME, EBSCO, DIALNET, MIAR, Latindex, QUALIS y Sistema de Clasificación de Revistas Mexicanas de Ciencia y Tecnología (Conacyt).
Desde 1977, Salud Mental ha buscado responder a las necesidades editoriales de los investigadores del área de la salud mental. Su línea de acción considera cuatro criterios fundamentales: educación continua, actualización, información y divulgación de los trabajos de los investigadores de la institución y externos con un enfoque multidisciplinario. A más de tres décadas de su fundación, se ha convertido en un foro para investigadores nacionales e internacionales de la psiquiatría, las neurociencias y la psicología (Figura 9). La revista es también un canal de comunicación científica internacional y está indexada en reconocidos índices nacionales e internacionales.

En 2012, la implementación del asistente editorial electrónico favoreció el aumento exponencial del número 


\section{ralud mented}

ralod mentel

\section{Dirección de Enseñanza}

\section{Departamento de Biblioteca Digital y Difusión Científica}

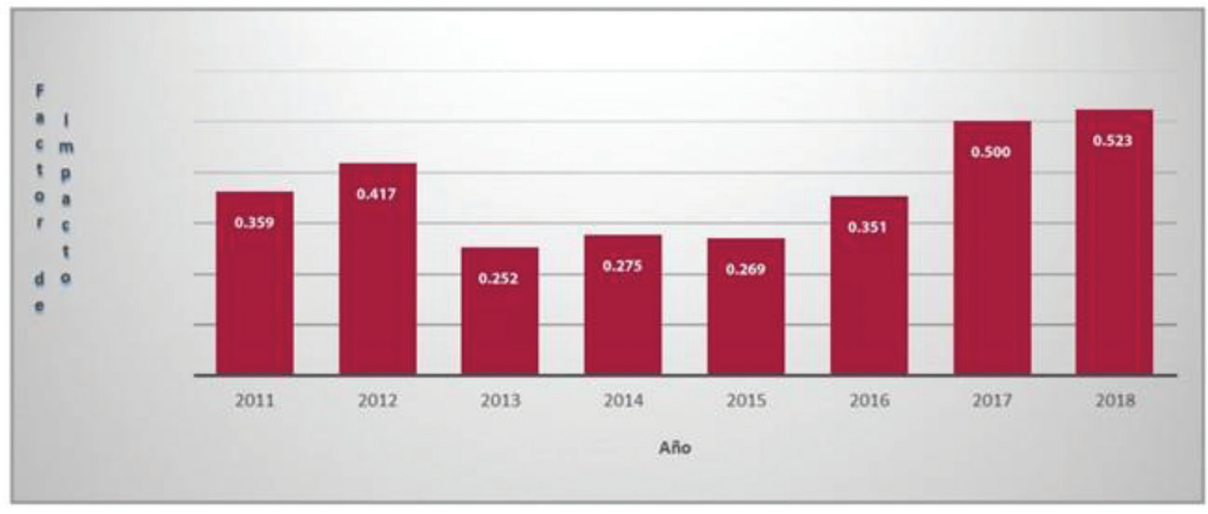

•FUENTE: InCites Journal Citation Reports Clarivate Analytics

\section{SALUD}

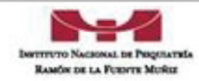

Figura 10. Evolución del factor de impacto de Salud Mental de 2011 a 2018.

de artículos sometidos a la revista. Esto, aunado al reducido personal operativo del equipo editorial, generó la necesidad de responder a este reto sin descuidar la calidad de sus contenidos. En ese momento, el análisis situacional de Salud Mental condujo a la ineludible necesidad de fortalecer el equipo editorial con la integración de nuevos miembros que coordinaran el trabajo editorial y evaluaran con mayor rigor la calidad de los manuscritos recibidos. Así, se implementaron nuevos procesos para optimizar los recursos humanos y económicos disponibles. Se creó un comité de evaluación interno, que revisa exhaustivamente cada manuscrito antes de ser evaluado por pares externos. Los requisitos metodológicos evaluados por el comité garantizan el impacto de la publicación.

La tasa de rechazo actual de la publicación es de 85 a $90 \%$ y todos los manuscritos dictaminados reciben retroalimentación. La implementación de este proceso ha permitido disminuir el tiempo de espera de muchos manuscritos y garantizar su calidad metodológica.

Los logros obtenidos en los últimos años son:

- Instalación del gestor editorial Open Journal Systems para gestionar y publicar la revista en un sitio web propio.

- Asignación del digital object identifier (DOI), que da mayor visibilidad a nuestras artículos y facilita las búsquedas en las bases de datos.

- Incorporación de un proceso sistematizado y riguroso de revisión metodológica por el comité de evaluación interno.

- Publicacion en inglés de los contenidos indexados, con la finalidad de favorecer su divulgación e incrementar su citación por la comunidad científica internacional.

- Implementación de una estrategia de divulgación de los contenidos en redes sociales y académicas. 
- Participación del equipo editorial de Salud Mental en los proyectos para la mejora continua de la publicación convocados por el Conacyt.

El reto actual de Salud Mental coincide con el de otras publicaciones latinoamericanas: convertirse en una opción competitiva entre las más de 3000 revistas del Social Science Citation Index (Journal Citation Report) de Web of Science (Figura 10), lo cual requiere un proceso de actualización hacia las tendencias y estándares que exige la publicación científica contemporánea. Para este propósito se requiere una relación estrecha entre los autores y los editores.

\section{Conclusiones generales}

La descripción de las seis revistas participantes en este simposio de la Academia Nacional de Medicina de México, documenta la historia e importancia que han tenido las revistas científicas mexicanas en la investigación clínica desde el siglo XIX. Los retos que enfrentan algunas de estas revistas son principalmente financieros, que reflejan la muy baja inversión en investigación en México que se ha vivido durante décadas y que se vislumbra poco optimista.

Los recientes factores de impacto del Journal Citation Reports correspondientes a 2019 muestran un incremento para la mayoría de las revistas, que no obstante sigue siendo menor a 1.0 para la mitad de ellas. Los cambios en el factor de impacto de estas revistas son los siguientes: Archives of Medical Research, 2.093; Revista de Investigación ClínicaClinical and Translational Investigation, 1.192; Gaceta Médica de México, 0.581; Cirugía y Cirujanos, 0.264; Salud Pública de México, 1.647; Salud Mental, 0.689. Annals of Hepatology, otra de las revistas mexicanas con factor de impacto se sitúa en 2.125.

Esperamos que la necesidad imperante de impulsar la investigación clínica y biomédica en México a raíz de la actual pandemia de COVID-19, de pie para que nuestras revistas aumenten la calidad y originalidad de sus contenidos y puedan incrementar su reconocimiento entre las comunidades científicas nacional e internacional, lo que les permita colocarse en un sitio digno de la estatura académica de sus investigadores.

\section{Conflicto de intereses}

Los autores declaran no tener conflicto de interés alguno.

\section{Financiamiento}

Los autores no recibieron patrocinio para llevar a cabo este artículo.

\section{Responsabilidades éticas}

Protección de personas y animales. Los autores declaran que para esta investigación no realizaron experimentos en seres humanos ni en animales.

Confidencialidad de los datos. Los autores declaran que en este artículo no aparecen datos de pacientes.

Derecho a la privacidad y consentimiento informado. Los autores declaran que en este artículo no aparecen datos de pacientes.

\section{Bibliografía}

1. Somolinos-Palencia J. Contribuciones mexicanas a la investigación médica. México: Universidad Nacional Autónoma de México; 1984.

2. Ramírez E. Nota preliminar sobre la citología del flujo menstrual. Rev Mex Biol. 1922;2:199.

3. Ramirez E. El ritmo sexual vaginal de la mujer. Rev Mex Biol. 1928;8:1.

4. Papanicolau GN. The sexual cycle in the human female as revealed by vaginal smears. Am J Anat. 1933;52:519.

5. Gómez-Dantés O, Retes L. Historia de Salud Pública de México. Salud Publica Mex. 1988;30:114-117

6. Rodríguez-de Romo AC, Rodríguez-Pérez ME. Historia de la salud pública en México: siglos XIX y XX. Hist Cienc Saude-Manguinhos. 1998;5:293-310

7. López-Moreno S, Oropeza-Abúndez C. Salud Pública de México: evolución de una idea. Salud Publica Mex. 1999;41:442-443.

8. Cruz A. Nombran a Salud Pública de México como mejor revista científica del país. México: Crónica [En línea] 2017 Sep 08.

9. Rivera-Dommarco J, Shamah-Levy T, Barrientos-Gutiérrez T, Bautista-Arredondo S, Romero-Martínez M, Pelcastre-Villafuerte B, Torres-Pereda $P$. La salud de los mexicanos que habitan en localidades de menos de 100000 habitantes. Salud Publica Mex. 2019;61:709-715.

10. Lazcano-Ponce E, Oropeza-Abúndez C. Terremotos, salud y sociedad: lecciones aprendidas. Salud Publica Mex. 2018;60:S2-S5.

11. Barrientos-Gutiérrez T, Alpuche-Aranda C, Lazcano-Ponce E, Pérez-Ferrer C, Rivera-Dommarco J. La salud pública en la primera ola: una agenda para la cooperación ante Covid-19. Salud Publica Mex. 2020;62.

12. Vega-Vega $O$, Arvizu-Hernández M, Domínquez-Cherit JG, Sierra-Madero J, Correa-Rotter R. Prevención y control de la infección por coronavirus SARS-CoV-2 (COVID-19) en unidades de hemodiálisis. Salud Publica Mex. 2020;62:341-347.

13. Gutiérrez-Castrellón P. Current challenges on the generation and dissemination of scientific evidence in health and how to translate it to health decision making. Cir Cir. 2020;88:247-248.

14. Wolfram D, Want $P$, Hembree A, Park H. Open peer review: promoting transparency in open science. Scientometrics 2020.

15. Ross-Hellauer T, Görögh E. Guidelines for open peer review implementation. Res Integr Peer Rev. 2019:4:1-12.

16. Sokal AD. Transgressing the Boundaries: Towards a Transformative Hermeneutics of Quantum Gravity. Social Text. 1996;46/47:217-252.

17. Bogdanov G, Bogdanov I. Topological field theory of the initial singularity of spacetime. Class Quantum Gravity. 2001:18:4341-4372.

18. Schon JH, Kloc C, Batlogg B. Retraction note to: superconductivity in molecular crystals induced by charge injection. Nature. 2003;422:93.

19. Gallo RC, Essex M, Gross L (editores). Human T-cell leukemia/lymphoma virus. EE. UU.: Cold Spring Harbor Laboratory; 1984.

20. Mehra MR, Desai SS, Ruschitzka F, Patel AN. RETRACTED: hydroxychloroquine or chloroquine with or without a macrolide for treatment of COVID-19: a multinational registry analysis. Lancet. 2020. 